$12-1-1997$

\title{
Anthroposophic perspectives in primary care
}

Ira S. Cantor MD

Thomas Jefferson University

Steven Rosenzweig MD

Thomas Jefferson University

Follow this and additional works at: https://jdc.jefferson.edu/emfp

Part of the Alternative and Complementary Medicine Commons Let us know how access to this document benefits you

\section{Recommended Citation}

Cantor, Ira S. MD and Rosenzweig, Steven MD, "Anthroposophic perspectives in primary care" (1997). Department of Emergency Medicine Faculty Papers. Paper 1.

https://jdc.jefferson.edu/emfp/1

This Article is brought to you for free and open access by the Jefferson Digital Commons. The Jefferson Digital Commons is a service of Thomas Jefferson University's Center for Teaching and Learning (CTL). The Commons is a showcase for Jefferson books and journals, peer-reviewed scholarly publications, unique historical collections from the University archives, and teaching tools. The Jefferson Digital Commons allows researchers and interested readers anywhere in the world to learn about and keep up to date with Jefferson scholarship. This article has been accepted for inclusion in Department of Emergency Medicine Faculty Papers by an authorized administrator of the Jefferson Digital Commons. For more information, please contact: JeffersonDigitalCommons@jefferson.edu. 


\title{
ANTHROPOSOPHIC PERSPECTIVES IN PRIMARY CARE
}

\author{
Ira S. Cantor MD \\ Steven Rosenzweig MD
}

\begin{abstract}
From the Steiner Medical and Therapeutic Center, Phoenixville; and the Division of Emergency Medicine, Jefferson Medical College, Thomas Jefferson University, Philadelphia, Pennsylvania
\end{abstract}

Address reprint requests to

Steven Rosenzweig, MD

Jefferson Medical College

Division of Emergency Medicine

Thomas Jefferson University

1020 Sansom Street

Philadelphia, PA 10197

\begin{abstract}
A core challenge of contemporary medicine is to integrate the technological successes of biomedical science with a comprehensive under-standing of the physical, psychosocial, ecological, and spiritual dimensions of health and illness. Toward this end, bridges are being created between conventional medicine and alternative systems of healing which reflect a holistic model of the human being.

Even when both conventional and complementary approaches are used side-by-side in the same patient, they remain separate in their basic assumptions and goals. Today's mechanistic disease model is cut off from such notions as life-energy, consciousness, and spirituality, so integral to many alternative paradigms.

Anthroposophically Extended Medicine (AEM) is a comprehensive healing system that successfully integrates biomedicine with a more complete understanding of human reality. Originating in Europe at the beginning of the 20th century, AEM has its roots in the Western, scientific worldview. By expanding this worldview, anthroposophy offers the clinician new possibilities for scientific investigation; it also creates bridges to the wisdom of older healing traditions of both East and West.
\end{abstract}

\section{BACKGROUND}

\section{Anthroposophically Extended Medicine Today}

AEM is well established in Western Europe and the United Kingdom, with inpatient facilities, research institutes, and an extensive network of outpatient practices. It has gained increasing recognition in the United States and Canada and in South America and Eastern Europe. 
AEM is not an alternative to conventional medicine, but rather an expansion. All anthroposophic physicians complete conventional training as doctors of medicine or osteopathy. They then learn anthroposophic diagnosis and therapy through intensive individual study. Postgraduate conferences and study groups are sponsored in the United States by the Physicians Association for Anthroposophic Medicine (see Appendix 1). Hospital-based training is available in Europe. Certification in the United States is offered through the North American Board of Anthroposophically Extended Medicine. In addition to allopathy, training draws on a knowledge of other healing methods, including homeopathy and naturopathy. AEM in turn contributes to these approaches through new insights into the preparation of homeopathic medicinals and into the relationship between natural substances and the human organism.

Ultimately, the defining of an anthroposophic physician lies not in the use of specific medicines or diagnostic tests, but rather in a unique view of the relationship between the human being, nature, and the cosmos.

\section{Rudolf Steiner, Anthroposophy, and the History of AEM}

Anthroposophy (anthropos [human being]; sophia [wisdom]) is a spiritual view of the human being developed by Austrian philosopher Rudolf Steiner, PhD (1861-1925). Steiner worked intensively to expand the boundaries of science to recover a deeper understanding of soul and spiritual processes. He showed that consciousness can be actively developed to perceive these subtle processes with increasing clarity. ${ }^{[39]}$ In collaboration with the Dutch physician Ita Wegman, MD (1876-1943) Steiner taught conventionally trained physicians to develop new therapeutic insights through a process of inner development and to explore scientifically the healing properties of natural substances using non-mechanistic concepts and phenomenological methods. He coauthored a core text with Wegman, ${ }^{\text {[42] }}$ lectured extensively on medical topics ${ }^{[34]}$ [35] [36] [38] [40] [41] and taught physicians at the bedside.

Steiner also worked with other therapists to bring about new directions in the healing arts. This activity brought about the development of anthroposophic schools of nursing, massage therapy, movement therapy (therapeutic eurythmy), hydrotherapy, and artistic therapies.

Steiner's work with pharmacists led to the discovery of new medicines and the development of innovative processes for harvesting the healing qualities of nature. One example is how the tumoricidal and immune enhancing effects of mistletoe were first investigated under the direction of Steiner. Pharmaceutical houses such as WALA and Weleda produce many medicines unique to AEM.

Integrally connected with these healing arts is Steiner's work in agriculture (biodynamic farming), and education (Waldorf schools), and therapeutic communities for neuropsychiatrically impaired children. Anthroposophic nurses, therapists, teachers, and pharmacists routinely work closely with physicians. 


\section{QUALITATIVE OBSERVATIONS IN SCIENCE}

Description is the foundation of all scientific study. We experience an object such as the heart and describe the qualities that strike us: size, structure, movement, relationship to other structures. From these descriptions we hypothesize and predict.

A next step is the attempt to quantify these descriptions and to reduce them to measurable phenomena. As critical as this reduction is, this translation of qualitative descriptions into quantitative data is always imperfect, and information is lost. A model that captures the pumplike activity of the heart excludes its "unpump"-like characteristics. ${ }^{[25][31]}$ As our models become more abstract, they are increasingly removed from raw experience.

It is therefore important to revisit the richness of our experience of an organ, an individual patient, or any object of study. This phenomenological approach gives rise to fresh insights and new hypotheses. A methodology of deepening and intensifying qualitative observations is evident in the writings of Johann Wolfgang von Goethe (17491832). Better known for his literary works, Goethe also produced important scientific treatises in optics, botany, anatomy, and zoology. ${ }^{[1] ~[5] ~[28] ~[37] ~ H i s ~ a p p r o a c h ~ h a s ~ b e e n ~}$ recognized by numerous scientists, including the biologist Stephen Jay Gould. ${ }^{[17]}$ Anthroposophically-oriented physicians and scientists have developed this method extensively into what has become known as Goethean science.

The examples of anthroposophic medical thought presented below illustrate this method of Goethean observation. In each case, we (1) bring into focus a particular phenomenon; (2) explore it qualitatively; and (3) redefine the phenomenon in broader terms suggested by these observations. Our discussion of these topics is limited, and we hope the reader will be interested in learning more. More comprehensive overviews of AEM are available. ${ }^{[6][13 \mathrm{~B}][19]}$

\section{INFLAMMATION}

\section{Normal Childhood Illnesses: Inflammation as Healthy Immune Activity}

Case \#1: L.M. is a 5-year-old boy with a history of recurent middle ear infections.they began at the age of 2 and typically followed upper respiratory illnesses. He has completed numerous courses of antibiotics. Initially he manifested acute inflammatory signs with these infections, including fever and erythema of the tympanic membrane. He no longer develops fevers, and his ear contains a serous effusion. He has chronic coryza and develops allergic conjunctivitis and wheezing on exposure to cats.

A principal task of childhood is the development of an independent self. Psychosocially, this is apparent in the necessary but challenging movement from mother's breast to homelike play settings and to increasingly independent school situations. Physiologically it is seen in the development of the immune system, a physical reflection of the self. For example, while initially relying on maternal antibodies in the blood, the infant gradually develops independent humoral immunity. 
Common childhood illnesses are key challenges along the way. While these are necessary milestones to mature immunity, they of course represent some danger as well. The physician, like the wise parent or educator, must perceive whether or not a particular challenge can be met by a child. Too much interference from a parent whenever a difficulty is encountered will produce a weak-willed child. Similarly, unnecessary intervention on the part of a physician will lead to a disordered, weakened immune system. Consequences of excessive intervention are evident today in numerous children similar to the one described above. There are two hallmarks of disturbed immunologic function in such children: frequent recurrent infections and prominence of allergic disorders.

Inflammation represents a normal healing response of the organism. When it occurs in a healthy way, the child's immune system matures, a picture of the self gaining a firmer grasp of the organism as it interacts with the environment. However, repeated suppression of inflammation with antipyretics and antiinflammatory agents undermines the child's ability to mount a healthy response to pathogenic challenges. One possible consequence is the absence of significant fever when illness recurs. Another possible consequence is a subacute state of aberrant, low-grade inflammatory response typical of atopic conditions.

Typical childhood illnesses represent a necessary process of immune maturation, and this process in turn reflects the greater task of a child developing a competent, independent self, both physically and spiritually. The approach of an anthroposophic physician therefore differs significantly from the more limited goal of preventing and treating symptoms of illness. Fevers, for example, are not routinely suppressed with antipyretics unless the child cannot handle the catabolic consequences of this strong immune response. This approach is supported by ample scientific evidence demonstrating adaptive value of fever and the immune-suppressant effects of antipyretics. ${ }^{[10][18][22] ~[23]}$

\section{Some Effects of Febrile Temperatures on Host Defense Responses ${ }^{\mathrm{F}}$}

Enhanced neutrophil migration

Increased production of antibacterial substances

by neutrophils (e.g., superoxide anion)

Increased production of interferon

Increased antiviral and antitumor activity of interferon

Increased T-cell proliferation

Decreased growth of microorganisms in iron-poor environment 
Instead, the child's inflammatory response can be supported and guided through the use of lemon calf wraps, ${ }^{[46]}$ sponging, or homeopathically prepared medicines such as ferrum phosphoricum (phosphor iron).

Antibiotics are prescribed much less frequently than in conventional practice. Although absolutely necessary in some situations, antibiotics do override, often prematurely, the organism's own effort to reestablish homeostasis. ${ }^{[30]}$ [43] [44] $^{[4 h i s ~ i s ~ a g a i n ~ a ~ p i c t u r e ~ o f ~ n o t ~}$ allowing the host immune response to mature and strengthen fully. It is important to minimize use of antibiotics also because of their detrimental effect on normal body flora, leading to Candida overgrowth, diarrhea, digestive disturbances, and emergence of resistant organisms. Finally, the allergenic potential of antibiotics also must be kept in mind.

Although the obvious question of the viral or bacterial nature of an illness is considered, other aspects come into consideration. How is the child coping with the challenge? Can botanical or homeopathic medicines be used to support, rather than suppress, the child's immune response? Can the child's home situation provide the necessary love, care, and protection necessary for working through the illness in the most beneficial way?

\section{Preventive Medicine: Understanding the Polarity of Inflammation and Sclerosis}

AEM observes a polarity between inflammation and sclerosis. Qualitatively, inflammation is an exaggerated picture of the normal physiologic tendency of childhood: warmth and ruddiness, robust metabolic activity, rapid change, plasticity, turgor. Sclerosis, on the other hand, is an extreme picture of the physiologic tendency at the other end of life: coolness, constrained metabolic activity, slow change, hardening, dryness (Table 1). In fact, health reflects a dynamic balance between tendencies toward

TABLE 1 -- POLARITY OF INFLAMMATION AND SCLEROSIS

\begin{tabular}{|l|l|}
\hline Inflammation & \multicolumn{1}{|c|}{ Sclerosis } \\
\hline Warmth & Coolness \\
\hline Rubor & Pallor \\
\hline Robust metabolic activity & Diminished metabolic activity \\
\hline Rapidly changing & Slowly changing \\
\hline Dissolving process (inflammatory exudate) & Hardening process (plaque formation) \\
\hline Prominent in childhood & Prominent in later years \\
\hline Less prominent in year years & Less prominent in childhood \\
\hline
\end{tabular}

From Kluger, MV Kozak W, Conn CA, et al: The Adaptive value of fever. Inf Dis Clin North Am 10:1-20, 1996; with permission.

inflammation and sclerosis in each phase of life. ${ }^{[19]}$ For example, although a picture of inflammation predominates in childhood, normal sclerosing activity also takes place, including tooth and bone formation. 
The tendency toward inflammation or sclerosis is apparent when comparing the illnesses of childhood with those of later years. In contrast to the typical febrile illnesses of youth, the elderly manifest such diseases as atherosclerosis, degenerative disorders of bone and nerve, and the formation of solid tumors.

This schema is helpful in examining the range of chronic inflammatory diseases, such as arthritis, asthma, chronic sinusitis, and various autoimmune disorders. The qualities of acute inflammations are drastically different from these chronic states. The former are characterized by total body involvement (fever, malaise), warmth, a copious exudative process that dissolves an offending substance (such as a foreign body or microorganism), rapid onset, and resolution. If the body's healing reaction is successful, no negative residua occur. In fact, the person usually is strengthened in the sense described above; an individual may even experience a sense of renewal. In contrast, chronic inflammatory conditions typically are localized and cool, with minimal serous effusions and accumulation of mineral-like substances (calcification, plaque). Instead of strengthening the organism, they debilitate. Seen in this way, chronic inflammatory conditions are pseudoinflammations; they are actually sclerosing illnesses.

The spectrum of illnesses in Western society has changed dramatically in the course of the century. Numerous factors have contributed to the marked decrease in the prevalence of acute inflammatory, infectious diseases; these include the widespread use of antimicrobials, immunizations, and effective hygienic practices. Concurrently, the prevalence of chronic inflammatory and sclerosing illnesses has risen just as significantly. The usual explanation of this latter fact is that people are simply living longer, and this is certainly one important factor.

However, it is also possible that a causal connection exists between the absence or suppression of acute inflammations and the subsequent development of sclerosing diseases. Recent reports suggesting a relationship between a paucity of acute childhood infections and the dramatic increase in asthma point in this direction. ${ }^{[7] ~[9] ~[33] ~ T h e ~}$ emergence of new kinds of infectious diseases, and the dramatically increasing prevalence of disorders of our immune system (manifesting as allergies and connective tissue diseases) may be related to these changes as well.

How does this pertain to preventive medicine? Characteristic of allopathic medicine is a strategy of opposing and suppressing symptoms of illness. Hence the extensive number of classes of medications carrying the prefix "an" or "anti," such as analgesics, anesthetics, antiinflammatories, antimicrobials, antipyretics, antispasmodics. These medications frequently undermine the body's own healing responses. (In fact, it is often the healing response of the organism, e.g., fever or diarrhea, that is targeted as an illness symptom.)

Anthroposophic physicians contend that overuse of suppressant therapies results in the impaired and deranged immune responses characteristic of allergic and chronic inflammatory conditions. These aberrant immune responses also underlie the chronic sclerosing illnesses of adulthood. Limiting the use of antibiotics and medications such as 
acetaminophen, ibuprofen, and prednisone may prevent later development of sub-acute or chronic sclerosing diseases.

Anthroposophic therapeutic strategies all recognize the patients' own capacity for selfhealing. At times this healing response can be supported and directed through the use of botanical and homeopathically prepared anthroposophic medicines that are less toxic than synthetic pharmaceuticals. At other times, the patient must be first rescued from a state of dangerous imbalance using antibiotics or other chemotherapeutic agents; self-healing then can be supported through complementary methods.

In the case of mild to moderate infections, it is often possible to support healing solely through botanicals such as echinacea, ${ }^{[2]}{ }^{[4]}$ homeopathically prepared medicines, diet modification, nutritional supplementation, compresses, and other external applications. ${ }^{[46]}$ These complementary approaches still play an important role even when antibiotics and antipyretics are required.

Another important area is the treatment of soft tissue injuries and inflammations. Here again the goal of therapy is not to suppress inflammation, but rather to guide, support, or modulate it. Acute sprains and strains generally respond well to such simple measures as rest and frequent applications of ice. If the overlying skin is intact, external compresses using tincture of Arnica montana or applications of arnica ointment can be used to reduce pain and swelling; arnica also can be taken orally in homeopathic form. ${ }^{[4]}$ Allowing the body its normal response to injury may facilitate a more rapid recovery phase.

Subacute conditions such as tendonitis, bursitis, and myofascial syndromes also can be treated using alternative methods. These are examples of stalled inflammations, which are unable to culminate in a completed healing response. Trigger point therapy using subcutaneous injections of homeopathically prepared substances have been found to be clinically effective. For example, injected microdilution of bee venom $(1: 100,000)$ is thought to transiently intensify a local inflammation, which then culminates and rapidly resolves.

Does a well-hydrated child who is sleeping at night "need" to have her fever aggressively suppressed with antipyretics? Does an adult with a lumbar strain, who remains ambulatory, "need" a 7-day course of ibuprofen in addition to ice, stretching, massage, and adjusted body mechanics? The potential risk of these routine suppressant therapies needs to be reconsidered.

\section{THE FOURFOLD HUMAN BEING}

AEM shares many ideas with other healing systems, including: support of the patient's potential for self-healing; existence of subtle energies; psychological and spiritual dimensions of illness; and treatment of each individual's unique constitution. Anthroposophy also brings many unique concepts to the healing arts. One insight is the fourfold organization of the human being. 
Conventional medicine's primary focus is on the physical body: its structure, biochemical composition, and function. The body as machine is a central metaphor. Parts break; they need to be fixed or replaced. Health means simply that nothing is broken at the moment. This approach has been enormously successful in the manipulation of physical processes through advanced technologies. It is at the same time profoundly limited, overlooking the more subtle aspects of our being that are less easily measured and quantified.

Not only are we physical beings, we are living beings. Weaving through the physical body are life processes such as metabolism, growth and decay, differentiation, selfregulation, homeostasis, and metamorphosis. Just as physiology is distinct from, but interconnected with, anatomic structure and biochemical composition, life processes interweave throughout our physical body. From an anthroposophic point of view, it is important to picture these processes as forming a distinct life-"body." The life- "body" can then be studied in terms of its own unique phenomena and laws. Plants, animals, and humans all have life-"bodies."

We are also conscious beings. Consciousness, or sentience, is the ca pacity to feel and react. On the subconscious; cellular level, sentience is reflected in information flow and metabolic reactivity. At the level of the psyche, sentience means that we are awake, inwardly experiencing our bodies and our world. Anthroposophy creates a picture of a sentient-"body" or soul-"body" with its own unique activity and laws. Animals and humans have sentient-"bodies."

Finally, we are self conscious. We directly experience our own individuality. Through this knowledge of self we create personal meaning, experience freedom, and enter into relationships with other individualities. This self, or "II" is a fourth, unique aspect of the human being.

A sense of these four layers of being is found in older healing systems. For instance, they relate to the ancient Greek notion of four fundamental elements or cosmic processes: Earth, Water, Air, and Fire (Appendix 2).

Anthroposophic physicians work to deepen their understanding and perception of how these four "bodies" interrelate and reveal themselves in health and illness. By retraining the mind's eye, qualities of the life-"body", the sentient-"body" and the " $I$ " can be discerned with increasing clarity. Clinical conditions can then be understood in a new way. Spasm, for instance, occurs when the sentient- "body" works too strongly within the life-"body." Hypersensitivity occurs when the relationship is loosened between the " $I$ " and the sentient-"body". Illness represents an opportunity to bring these subtle imbalances to light and to restore a harmonious in terplay among the four aspects.

\section{DIGESTION}

Case \#2: Ms. S.H. is a 43-year-old woman who has noted increasing fatigue along with abdominal bloating occurring with cramps and loose stools. She has had these symptoms intermittently for 10 years. The diarrhea occasionally alternates with constipation. 
Fatigue has worsened over the past few years, and is associated with difficulty in concentrating. She has also noted some mild depression and anxiety, and relates always "being on edge." Review of systems is positive only for chronic rhinitis. Past medical history is positive for recurrent episodes of vaginitis after she was placed on birth control pills in her 20s. Recurrent sinus infections have been treated with frequent courses of antibiotics.

She has consulted with numerous physicians. Laboratory evaluations including stool analyses for routine bacterial pathogens, ova, and parasites have been normal. Radiologic studies of the GI tract and colonoscopy were normal. She has been diagnosed with irritable bowel syndrome and depression, and has been on various therapeutic regimens, including fiber supplementation, antispasmodics, and antidepressants, without sustained success.

She had initiated on her own a food group elimination diet searching for food sensitivities, and had found that elimination of sugars, dairy products, and yeastcontaining foods such as vinegar and fermented products had improved her symptoms significantly.

This patient presents with very common complaints well known to primary care physicians. Conventional medicine is limited in its approach to many chronic syndromes, including functional disorders of the gastrointestinal tract. Standard treatment often is unsuccessful. In addition, such a patient's presentation typically is approached as a collection of disconnected gastrointestinal, immunologic, and psychiatric symptoms. By contrast, anthroposophically extended medicine seeks to identify the under lying processes that connect the various disturbances demonstrated by this patient. The emerging field of functional/nutritional medicine has made significant contributions toward the care of this type of patient. We will discuss certain concepts from this important field using an anthroposophic perspective.

\section{Anthroposophic Understanding of Digestion and Assimilation}

Using a Goethean approach of qualitative analysis, it is valid to discuss the phenomenon of digestion in a broad sense. By investigating the qualities of digestion, we can see it as a particular process not limited to the degradation and absorption of foodstuffs within the gut. Grasping the essential "gesture" of digestion, we can recognize this process as it takes place on other levels.

For example, one of the primary tasks of a human being is to confront, assimilate, and integrate new experiences. In the realm of education, we come up against new thoughts that we must process and eventually make our own. Compare someone who uncritically accepts ideas and falls under their influence with someone else who wrestles with and "digests" new ideas, and thereby integrates them into her own worldview.

On a physical level, a similar task is performed through the gastrointestinal tract. We ingest strongly allergenic substances, with a powerful "foreign" quality. The process of 
digestion in the upper intestinal tract is very much involved with the destruction and neutralization of this allergenic quality. We eat carrots or chicken and must degrade these foods so that nothing of the quality of "carrotness" or "chickenness" remains by the time the food reaches the small intestine. Carbohydrates and proteins are first broken down into more allergenically neutral saccharides, peptides, and amino acids before absorption through the small intestine wall. Fats, which are the least allergenic, are broken down into monoacylglycerols and diacylglycerols.

Food within the intestinal lumen still can be considered to lie "outside" the body; it must pass through the intestinal wall to truly enter inside. ${ }^{[15]}$ Products of fat digestion enter primarily into the lymph system, where they travel via the thoracic duct into the general circulation. Their relatively low allergenic quality doesn't require further processing. Products of protein and carbohydrate digestion travel via the portal vein to the liver, where there is a continuation of the processes of digestion and metabolism.

AEM develops a picture of the " $I$ " governing digestion of external substances, overcoming their foreign nature and assimilating them. This picture is somewhat comparable to that of the " $I$ " governing the immune system, maintaining the integrity of the host.

\section{Microbiology and Digestion}

The microbiology of the intestinal tract is of great importance to digestion. There are more microbes in the gut than cells in the entire body. This vast number of microorganisms perform many essential roles, ranging from production of various vitamins to protection from overgrowth of pathogenic organisms. Their distribution is significant: a large microbial population exists in the proximal tract up to the stomach. The area between the stomach and the large intestine contains a minimal bacterial population $\left(10^{3}\right.$ microbes per $\left.\mathrm{mL}\right)$. The large intestine again is extensively populated with microbes $\left(10^{12}\right.$ per $\left.\mathrm{mL}\right){ }^{[32]}$

Numerous factors can interfere with the healthy functioning of our digestive system. Poor diet, use of antibiotics, and chronic constipation, all widely prevalent in our society, can have significant consequences. Diet directly effects the microbial population of our gut. For example, subpopulations of colonic bacteria change according to the amount and types of fiber in our diet. These organisms produce short-chain fatty acids including butyric acid, a key nutrient necessary to colonic mucosal cells for their healthy functioning.

Use of antibiotics alters the normal microbial population, allowing pathogenic overgrowth of certain bacteria and yeast. ${ }^{[29]}$ This is recognized in Clostridium overgrowth as well as in the secondary yeast overgrowth that occurs in the digestive tract and the vagina.

Chronic constipation and certain bowel motility disorders may cause a migration of the microbial population from large intestine into small intestine. ${ }^{[21]}$ This can be documented by breath tests that evaluate small bowel bacterial overgrowth (available through Great 
Smokies Diagnostic Laboratory, Asheville NC). Use of these tests in certain patients suggests that constipation need not be extreme to produce clinically significant overgrowth, contrary to the conventional view.

\section{Special Role of the Liver}

Embryologically, the liver develops as an outgrowth of the primitive gut, revealing its intimate relationship to the digestive process. However, it also is set apart from the GI tract, suggesting a distinct role.

The body's largest gland has many complex functions. One role of the liver in digestion is the formation and secretion of bile. Another key hepatic "digestive" function is detoxification. Toxic substances are neutralized through the cytochrome P450 system and conjugation reactions (e.g., sulfation, glucuronidation, and glycination). Nitrogenous waste is detoxified and excreted through the urea cycle. Phagocytic Kupffer cells normally "digest" $99 \%$ of colonic bacteria that pass into the body through the portal vein.

The liver is also a transition point between degradation processes of digestion and anabolic activity. Short-chain fragments are transformed into human protein, glycogen, and fat. Energy production occurs through the Krebs cycle, which also functions to provide intermediates for synthesizing amino acids and porphyrins. Through regulation of glycogen, the liver participates in energy regulation throughout the body.

Viewed qualitatively, the liver is not only a digestive organ, but the seat of substance building and energy forming processes. Its remarkable self-healing ability after injury further conveys this harboring of regenerative capacity. Its detoxifying function can be seen also as restorative activity. Stepping back from such abstract concepts as anabolism and ATP production, the liver can be described in terms of formative, energetic, regenerative, and restorative qualities. Its name meaning "life-giver," these observations suggest the liver as governing the aliveness and vitality that permeates the entire organism. The liver is a key organ for understanding the activity of the life- "body."

By viewing liver processes in this expanded way, a subtle liver problem can be suspected in certain patients with symptoms such as food sensitivities, fatigue, and mild depression. Medical history, examination, and careful patient observation may suggest a liver problem. Conventional liver function tests may be normal in these cases, being more sensitive for injury than for dysfunction. Functional testing of liver detoxification pathways (Great Smokies Diagnostic Laboratory) may identify abnormalities in these patients.

\section{Mind-Body Interaction}

Functional disorders of the gastrointestinal tract are highly prevalent. These conditions, in which no structural or constant biochemical derangement can be identified, include: esophageal disorders (globus, heartburn, dysphagia); gastroduodenal disorders 
(dyspepsia); bowel disorders (irritable bowel, bloating); and abdominal pain, gallbladder dysfunction, anorectal disorders (functional incontinence, anorectal pain, dyschezia).

The term functional implies that a true derangement exists even though it is not captured by conventional testing methods. Objective diagnostic criteria are subtle. Growing research points to the pathogenic contribution of visceral sensorimotor and central nervous system dysregulation in these syndromes. ${ }^{[11]}$ Stress plays a key role in progression and exacerbation of symptoms, which often respond to mind-body therapies such as meditation, biofeedback, and hypnosis. ${ }^{[47]}$

From an anthroposophical standpoint, body and mind are reflections of a unified reality. In this sense, all illness is psychosomatic or somatopsychic. The interweaving of consciousness ("I" and sentient-"body") with physiology (life-"body" and physical body) is evident not only through the nervous system, but also throughout the metabolic realm. The capacity to sense and respond to change is as integral to cellular metabolism as to psyche and spirit.

Anthroposophic physicians work with an awareness of the four "bodies" as a way of understanding the mind-body interplay. A patient may not be sufficiently self-aware in the psychological realm, indicating a problem in the relationship between the " $I$ " and the sentient-"body." Or, he may be "too awake" in the intestine or other areas within the metabolic realm, suggesting discord between life-"body" and sentient-"body." These phenomena can be treated metabolically through anthroposophic medicines, massage, or movement therapy, or psychospiritually through meditative exercises, artistic therapies, or psychotherapy.

Returning to Case \#2, consider the patient's so-called "irritable" bowel. Patients who carry the functional diagnosis of irritable bowel syndrome may still be suffering from subtle disturbances not investigated through a conventional work-up. When a person exhibits irritability or hypersensitivity in any domain, the physician needs to ask two key questions: What irritants are provoking the reaction? Why might this patient's constitution be more sensitive to these factors than that of a healthy individual? For this patient, several key issues can be identified:

\section{Food sensitivities.}

The patient discovered, on her own, that she was sensitive to certain foods. In the context of the above discussion, this suggests that something of the foreign quality of the foods is

not being completely neutralized through the digestive processes. ${ }^{[15]}$ There is controversy in the medical literature regarding the prevalence and significance of food sensitivity or food intolerance. Certain illnesses such as ulcerative colitis may be associated with a lower incidence of food sensitivity, whereas irritable bowel syndrome and others may be associated with a much higher incidence. ${ }^{[3]}$

Altered microbiology (dysbiosis) of the intestinal tract.

Her history of frequent courses of antibiotics has likely led to abnormal overgrowth of yeast and certain bacteria. Periods of constipation also may contribute to dysbiosis through redistribution of organisms into normally sterile areas of the intestine. 
Stress.

She reported symptoms of mild depression and anxiety, always "feeling on the edge." These are signs of a stress syndrome that likely contributed to the severity of her intestinal symptoms. In turn, her physical distress would be expected to act as an additional, powerful stressor.

These three factors compromise the digestive process enough to cause the "local" symptoms of pain and disordered motility associated with irritable bowel syndrome. These patients also suffer constitutional symptoms, which are discussed next.

\section{Systemic Effects of Disordered Digestion}

The various disturbances discussed above may lead to altered absorption and certain deficiency syndromes. The absorption of nutrients such as minerals can be impaired. This can further disturb the digestive process, because these minerals can be essential for enzyme production and absorptive function. This is especially true with such minerals as zinc, magnesium, and selenium. ${ }^{[8][15]}$ More systemic effects also can be seen. Magnesium, for example, is involved in over 200 different enzymatic reactions; deficiencies can lead to widespread effects.

On the other hand, there is evidence that dysbiosis may abnormally increase intestinal permeability to larger molecules, which have an undigested toxic element. This is the socalled "leaky gut syndrome." ${ }^{[15]}$ One consequence of leaky-gut is the abnormally high load of undigested material presented to the liver. It is hypothesized that this negatively affects global liver function, including energy production. The liver may not handle the load adequately, allowing toxic substances to provoke immunologically related symptoms, discussed below. Impaired global hepatic function may partially underlie complaints of fatigue and depression as the patient experiences diminished vitality.

Patients with disorders of digestion frequently present with a perplexing constellation of constitutional complaints. The hypothesis that they are being challenged by the presence of undigested substances sheds some light on the relationship among these symptoms, which are interesting to compare with those of infectious diseases. Typical infectious syndromes are produced by the body's response to a foreign microbe. Myalgias and fatigue result from the interaction between effects of the foreign organism and the body's defensive reaction. In a parallel way, we can recognize similar symptoms in many chronic illnesses, such as chronic fatigue and fibromyalgia, particularly if food sensitivities and gut dysbiosis are playing a role (Table 2 ). If we view undigested substances as foreign, just as we view invading microorganisms as foreign, we can expect that the body will react defensively against them, producing immunologically mediated syndromes. 


\section{Therapeutic Strategies}

Therapeutic approaches based on an anthroposophic understanding of digestion are often successful. Poorly tolerated food(s) can be identified

TABLE 2 -- PARALLELS BETWEEN ACUTE INFLAMMATIONS AND CHRONIC SCLEROSING ILLNESSES

\begin{tabular}{|l|l|}
\hline Acute Inflammatory Syndrome & \multicolumn{1}{c|}{ Chronic Sclerosing Syndrome } \\
\hline Example: Influenza infection & Example: Fibromyalgia \\
\hline Acute myalgias & Chronic myalgias \\
\hline Acute fatigue & Chronic fatigue \\
\hline $\begin{array}{l}\text { Acute cognitive difficulties (e.g., poor } \\
\text { concentration) }\end{array}$ & $\begin{array}{l}\text { Chronic cognitive difficulties (e.g., poor } \\
\text { concentration) }\end{array}$ \\
\hline Malaise & Depression \\
\hline
\end{tabular}

and removed, often through an elimination diet. ${ }^{[3][12][13][20]}$ A key anthroposophic strategy is to strengthen those processes that 0vercome the foreign quality of ingested substances. Herbal preparations from gentian root, ginger, and wormwood strengthen digestion through stimulation of digestive enzyme secretion. If excessive bacteria, yeast, or protozoa are found on comprehensive stool studies (Great Smokies Diagnostic Laboratory), antimicrobial medications can be helpful in restoring normal bowel ecology. ${ }^{[14]}[16]$ These can be from synthetic or botanical sources (e.g., grapefruit seed extract or ginger ${ }^{[2]}$ )

The liver can be treated directly in order to further improve digestion and also strengthen the vitalizing activity of the life-"body". An enormous amount of the liver's metabolic activity is dedicated to detoxification. This metabolic burden can be reduced, resulting in more efficient energy regulation and an enhanced sense of well being. Diet modification, elimination of alcohol and other hepatotoxins, and use of various botanicals are all important. Milk thistle ( Silybum marianum), for example, has been shown to support detoxification, protect the liver itself from toxic injury, promote hepatocellular regeneration, and improve liver function in hepatic disease. ${ }^{[2]}{ }^{[4]}\left[{ }^{[15] ~[27] ~ H e p a t a d o r o n, ~ a n ~}\right.$ anthroposophic preparation composed of wild strawberry and grape leaves, is another general supportive treatment for the liver. ${ }^{[19]}$

Hypersensitivity of the patient's overall constitution can be treated through therapies that harmonize the activity of the sentient-"body" Chamomile is an example of a metabolic treatment for intestinal cramps ${ }^{[45]}$ a sign of heightened visceral reactivity. It can be applied as an external compress, administered as a tea, or prescribed as an anthroposophic preparation given orally or by injection. AEM understands the qualities of chamomile to be helpful in regulating the interaction between life-"body" and sentient- 
"body". Stress reduction, meditation, artistic therapies, and movement therapy (eurythmy) serve to bring the sentient-"body" back under the guidance of the "I".

At the heart of all treatment is a recognition of the patient's "I" as it works deep within the organic processes as well as in the psychospiritual realm. Anthroposophic therapy addresses the inner freedom of the human being to find her or his path toward healing. Metabolically, therapies reflect the unique constitution of the individual; their aim is to facilitate self-healing. Spiritually, the individual is supported in the search for meaning in the face of suffering. Self-reflection, relationship work, contemplation, and spiritual studies light a path toward healing transformation.

\section{RHYTHM AND BALANCE}

\section{Working With Unifying Principles}

Reductionism and holism reflect two complementary movements of the mind's eye. Through the reductionistic gaze the human being is dissembled into increasingly small components: systems, organs, cells, biochemicals. The counter movement of holism restores the relationship of part to whole: Somehow this bag of biomolecular reactions organizes and integrates into ascending orders of complexity, resulting in the bio-psychosocio-spiritual human being.

Thinking holistically requires the discovery of unifying principles that weave parts into a whole. This means that they must also span the many levels of the human being, working on macroscopic and microscopic scales.

\section{Polarity}

Polarity is a key principle within our spiritual, psychological, and physical organization. Experientially we continually find ourselves poised between opposing tendencies: freedom versus commitment, contemplation versus action, idealism versus pragmatism. Our humanness is expressed in the ability to mediate between opposites and bring them into balance. We introduced an example of physiologic polarity in our earlier discussion of inflammation versus sclerosis.

Anthroposophy further develops this idea of polarity through recognition of a third, rhythmic process that mediates between two polar extremes. Physiologically, three interrelated systems or processes can be described: metabolic system, nerve-sense system, and rhythmic system

\section{Metabolic versus Nerve-Sense Process}

A broader understanding of physiologic polarity is apparent when contrasting the qualities of the digestive organs with those of the nervous system. For instance, we can compare liver and brain. The liver has enormous vitality, displaying abundant 
regenerative ability. This allows the liver to survive in stressful physiologic situations as it confronts the numerous toxic substances constantly passing through it. The liver can with-stand states of decreased blood flow and low oxygenation. In contrast to the resilient and regenerative quality of the liver, brain cells are very fragile and possess little inherent vitality; no new neurons are produced after the early part of the embryologic period. Whereas the liver can survive in rapidly changing situations, the brain requires a constant environment rich in oxygen and glucose.

Liver has a highly fluid quality, with a solid-to-liquid ratio only marginally greater than that of blood. Its lobular structure is not highly differentiated. By contrast, brain and sensory organs are hardened, highly structured and differentiated.

The liver and digestive organs manifest a preponderance of metabolic qualities. This is in contrast to the nerve-sense qualities of brain and nervous system. Typical of metabolic activity are qualities of movement, fluidity, warmth. Typical of nerve-sense activity are qualities of static form, dryness, coolness. The polarity of inflammation versus sclerosis now can be better understood: Inflammation can be considered as an extreme tendency of the metabolic process, while sclerosis may be seen as an extreme tendency of the nervesense process. ${ }^{[19]}$

Tension and interplay between metabolic and nerve-sense activity is apparent throughout every part of our organism. Even though the brain is primarily a nerve-sense organ, cerebral parenchymal cells certainly have metabolic qualities. The converse is true with the liver; despite their dominant metabolic function, hepatocytes are structured in such a way as to appropriately "sense" the signals of ingested substances and circulating hormones. Many organ systems in our body find a position between these two extreme poles. Our respiratory system, for example, shows this intermediate position. The upper part of the respiratory tree, including pharynx and trachea, is richly innervated and highly responsive to neuronal activity. Alveoli, on the other hand, are shaped and function as glands, which are typical metabolic structures.

\section{Rhythmic Process}

Mediating between metabolic and nerve-sense poles is a third, rhythmic process that brings about dynamic, healthy balance. Physiologically, there are many processes regulated in a rhythmic manner. Consider the feedback loops of our endocrine system. Thyroid hormone levels never remain static, but are constantly fluctuating. The complex interplay between TSH and thyroid function results in a continual oscillation of hormone production; thyroid function tests provide only a "snapshot" of what in reality is a dynamic physiologic system.

Fundamental, rhythmic processes are also readily apparent within the cardiovascular system (systole/diastole; blood pressure regulation) and respiratory system (inspiration/expiration; gas exchange). Within the nervous system there is modulation between depolarization and repolarization, excitation and recovery, arousal and sleep. Chronobiologic rhythms are integral to all physiologic systems, and attention to the 
rhythmic nature of our own being reveals our intimate relationship to the rhythms of the natural world around us.

Understanding of this rhythmic, balancing quality of all living systems is part of many alternative systems of healing. Asian medicine, for instance, represents the balancing of $Q i$, life energy, through the interrelationship of Yin and Yang. An ancient symbol of Western medicine, the staff of Aesculapius/Mercury, also expresses this insight of rhythmic movement, with the serpent wrapping itself around alternating sides of the central, healing staff.

Anthroposophic medicine works extensively with an understanding of these three processes: Metabolic activity at one pole, nerve-sense activity at the opposite pole, and rhythmic activity mediating in between. Disease occurs when balance is lost. For instance, migraine headache presents a picture of the nerve-sense pole overcome by metabolic processes. ${ }^{[19]}[42]$ "Undigested" food substances (chianti) or "undigested" sensory stimuli (glare, smells, noise) can provoke a migraine. Emotional upset or other stressors can irritate nerve-sense activity and provoke hypersensitivity. A breakthrough of metabolic process is evident in the chemical inflammation of cerebral blood vessels and plasma leakage. ${ }^{[24]}{ }^{[26]}$ The rhythmic, protective nature of blood circulation is lost through a combination of spasm and microvascular occlusion secondary to platelet aggregation. Treatment strategies are directed at restoring balance: The metabolic pole is approached through strengthening of digestive processes as discussed earlier in this article. Anthroposophic medicines can be used to harmonize metabolic and nerve-sense processes. Mind-body therapies restore balance through the nerve-sense pole.

Therapeutic measures that enhance all aspects of healthy rhythmic activity are fundamental to the counseling that an anthroposophic physician provides. This begins with parent education about establishing rhythms of waking, sleeping, and eating for the young infant. These are changing, living rhythms, not fixed and mechanical. Discussions about nutrition should always have the quality of balance in mind. Counseling continues with discussions regarding balance between work and play according to each individual's unique constitution. Each person's life must integrate with rhythms of family and workplace as well as with the larger rhythms of day, month, and year.

\section{CONCLUSION}

AEM emerged this century as a truly integrative healing system, a way of moving the boundaries of medicine beyond an exclusively biochemical, mechanical view of the human being. Its approach brings together insights from allopathy, naturopathy, homeopathy, and other schools of healing. The unique qualities of living systems, the nature of consciousness, and the reality of the self can be fully investigated only within an expanded scientific framework. These phenomena are essential for understanding the nature of human illness and healing.

It is critical for medicine to struggle with the question of what a human being is. We are not machines or kettles of biochemical soup. The tasks of the self are as relevant to our 
immunology and digestion as they are to our psychology and social life. Human individuality and freedom must be met with therapies that support self-healing rather than those that emphasize external intervention.

Health reflects our capacity to harmonize opposing tendencies in all realms, a very human activity of mediation and relationship building.

Healing emerges through the rhythmic balancing of systole and diastole, contraction and expansion, blood and nerve, matter and spirit.

\section{References}

1. Amrine F, Zucker FJ, Wheeler H (eds): Goethe and the Sciences: A Reappraisal. Boston, D, Reidel, 1987

2. Balick M, Duke J, et al: Herbal medicine. In Alternative Medicine: Expanding Medical Horizons. Washington, U.S. Government Printing Office, 1994, p 188

3. Bischoff SC, et al: Prevalence of adverse reactions to food in patients with gastrointestinal disease. Allergy 51:811-818, 1996

4. Blumenthal M, Gruenwald J, Hall T, et al: German Commission E Monograph: Therapeutic Monographs on Medical Plants for Human Use. Austin TX, American Botanical Council, 1997

5. Bortoft H: The Wholeness of Nature. Spring Valley NY, Floris Books, 1996

6. Bott V: Spiritual Science and the Art of Healing: Rudolf Steiner's Anthroposophical Medicine. Spring Valley NY, Healing Arts Press, 1996

7. Cookson WOCM, Mofatt MF: Asthma: An epidemic in the absence of infection? Science 275:41-42, 1997

8. Doe, WF: An overview of intestinal immunity and malabsorption. Am J Med, 67:1077-1084, 1979

9. Doll R: Health and the environment in the 1990's. Am J Public Health, 82:933941, 1992

10. Doran TF, De Angelis C, Baumgardner RA, et al: Acetaminophen: More harm than good for chickenpox? J Pediatr 114:1045-1048, 1989

11. Drossman DA (ed): The Functional Gastrointestinal Disorders: Diagnosis, Pathophysiology and Treatment. New York, Little, Brown, 1994 
12. Egger J, Carter CM, Graham PJ, et al: Controlled trial of oligoantigenic treatment in the hyperkinetic syndrome. Lancet 1:540-545, 1985

13. Egger J, Carter CM, Wilson J, et al: Is migraine food allergy? Lancet 2: 865-868, 1983

13B.Evans M, Rodger I: Anthroposophical Medicine: Healing for Body, Soul and Spirit. London, Thorsons, 1992. Available through St. Luke's Medical Centre, 57A Cainscross Road, Stroud, Glos., GL5 4EX, UK

14. Galland L: Intestinal protozoan infection is a common unsuspected cause of chronic illness. J Adv Med, 2:539-552, 1989

15. Galland L: Leaky Gut Syndromes. Townsend Letter for Doctors 145:62-68, 1995

16. Galland L, Barne S: Intestinal dysbiosis and the causes of disease. J Adv Med 6:67-82, 1993

17. Gould SJ: More light on leaves. In Eight Little Piggies. New York, WW Norton, 1994

18. Graham NMH, Burrell CJ, Douglas RM, et al: Adverse effects of aspirin, acetaminophen, and ibuprofen on immune function, viral shedding, and clinical status in rhinovirus-infected volunteers. J Infect Dis 162:1277-1282, 1990

19. Husemann F, Wolff O: The Anthroposophical Approach to Medicine, Volumes 13. Spring Valley NY, Anthroposophic Press, 1982

20. Jackson PG et al: Intestinal permeability in patients with eczema and food allergy. Lancet 1:1285-1286, 1981

21. Kirsch, M: Bacterial overgrowth. Am J Gastroenterol 85:231-237, 1990

22. Kluger MJ: Fever revisited. Pediatrics 90:846-850, 1992

23. Kluger MJ, Kozak W, Conn CA, et al: The adaptive value of fever. Infect Dis Clin North Am 10:1-20, 1996

24. Lance JW: Current concepts on migraine pathogenesis. Neurology 43: S11-S15, 1993

25. Marinelli R, Furst B, van der Zee H, et al: The heart is not a pump: A refutation of the pressure propulsion premise of heart function. Frontier Perspectives 5:15-24, 1995 
26. Moskowitz MA: Neurogenic inflammation in the pathophysiology and treatment of migraine. Neurology, 43:S16-S20, 1993

27. Murray M: Silymarin protects and aids the liver in detoxification reactions and chemical sensitivities. Phyto-Pharmica Review, Green Bay WI, Phyto-Pharmica, Fall 1987

28. Naydler J (ed): Goethe on Science: An Anthology of Goethe's Scientific Writings. Spring Valley NY, Floris Books, 1996

29. Nord CE, Kager L, Heimdahl A et al: Impact of antimicrobial agents on the gastrointestinal microflora and the risk of infections. Am J Med 76:99-106 1984

30. Pichichero ME: Group A streptococcal tonsillopharyngitis: Cost-effective diagnosis and treatment. Ann Emerg Med 25:390-403, 1995

31. Russek LG, Schwartz GE: Energy cardiology: A dynamical energy systems approach for integrating conventional and alternative medicine. Advances 12:424, 1996

32. Saltzman JR, Russell RM: Nutritional consequences of intestinal bacterial overgrowth. Compr Ther 20:523-530, 1994

33. Shirakawa T, Enomoto T, Shimazu S, et al: The inverse association between tuberculin responses and atopic disorder. Science 275:77-79, 1997

34. Steiner R: Anthroposophical Spiritual Science and Medical Therapy. Spring Valley NY, Mercury Press, 1991

35. Steiner R: Course for Young Doctors. Spring Valley NY, Mercury Press, 1994

36. Steiner R: Fundamentals of Anthroposophical Medicine. Spring Valley NY, Mercury Press, 1986

37. Steiner R: Goethean Science. Spring Valley NY, Mercury Press, 1988

38. Steiner R: Health and Illness, Volumes 1 and 2. Spring Valley NY, Anthroposophic Press, 1981

39. Steiner R: How to Know Higher Worlds. Spring Valley NY, Anthroposophic Press, 1994

40. Steiner R: Physiology and Therapeutics. Spring Valley NY, Mercury Press, 1986

41. Steiner R: Spiritual Science and Medicine. Blauvelt NY, Steinerbooks, 1989 
42. Steiner R, Wegman I: Extending Medical Practice: Fundamental Principles Based on the Science of the Spirit, London, Rudolf Steiner Press, 1997.

43. Strom J: Penicillin in the prevention of scarlet fever. Acta Paediatr 43:38-42, 1954

44. Strom J: Penicillin treatment and immunity to scarlitina. Acta Paediatr, 43:267279,1954

45. Tyler VE: Herbs of Choice: The Therapeutic Use of Phytomedicinals. New York, Pharmaceutical Products Press, 1994

46. van Bentheim T, Bos S, de la Housaye E, et al: Caring for the Sick at Home. Spring Valley NY, Floris Books, 1987

47. Whitehead WE, et al: Effect of stressful life events on bowel symptoms: Subjects with irritable bowel syndrome compared to subjects without bowel dysfunction. Gut 33:825, 1992

\section{APPENDIX 1}

\section{Selected Anthroposophic Healthcare Organizations}

Physicians Association for Anthroposophical Medicine

1923 Geddes Avenue

Ann Arbor, MI 48104

(313)930-9462

Artemesia

PO Box 3392

Chapel Hill, NC 27515-3392

(919)933-0940

Medical Section at the Goetheanum

School for Spiritual Science

CH-4143 Dornach

Switzerland

Weleda Pharmacy

PO Box 249

Congers, NY 10920

(800)241-1030 
Raphael Pharmacy (WALA)

7957 California Avenue

Fair Oaks, CA 95628

(800)677-0015

\section{APPENDIX 2}

\section{Western Four-Element Theory and the Fourfold Human Being}

The four Elements of Earth, Water, Air, and Fire (Warmth) have been discussed in Western philosophy from the Pre-Socratics up until the modern period. These represent fundamental organizing principles that weave through the human being, nature, and cosmos.

By means of Goethean investigation we can observe qualities in ourselves and the world that relate to these four Elements, suggesting the correlations noted below. Fuller discussion of these ideas is found in many anthroposophic writings.

TABLE

\begin{tabular}{|l|l|l|}
\hline Element & State of Matter & Human Being \\
\hline Earth & solid & physical body \\
\hline Water & fluid & life-"body" \\
\hline Air & gas & sentient-"body" \\
\hline Fire (warmth) & (no state; pure energy) & "I" \\
\hline
\end{tabular}

